Tropical Journal of Pharmaceutical Research, June 2009; 8 (3): 239-245

(C) Pharmacotherapy Group,

Faculty of Pharmacy, University of Benin

Benin City, 300001 Nigeria.

All rights reserved.

Research Article

Available online at http://www.tjpr.org

\title{
Effect of Coating Solvent Ratio on the Drug Release Lag Time of Coated Theophylline Osmotic Tablets
}

\section{Kanakal*, MHF Sakeena, MN Azmin, and D Yusrida}

Department of Pharmaceutical Technology, School of Pharmaceutical Sciences, Universiti Sains Malaysia, 11800, Pulau.Pinang, Malaysia.

\begin{abstract}
Purpose: The aim of the study was to investigate the effect of hydro-alcohol coating solvent ratio on the surface texture and lag time of porous theophylline osmotic tablet.

Methods: Porous theophylline osmotic pump tablets were formulated by direct compression and coated by spraying with varying ratios of water-alcohol containing hydroxypropyl methylcellulose (HPMC, 5 cps) as primary swelling layer and Eudragit ${ }^{\circledR}$ RSPO and RLPO as porous layer. The viscosity of HPMC coating solution was determined using Brookfield viscometer. Surface morphology was investigated with scanning electron microscopy (SEM). In vitro drug release studies to assess lag time was performed in simulated gastric fluid (SGF) and simulated intestinal fluid (SIF).

Results: No significant change in the viscosity of HPMC coating solution was found when water-alcohol solvent ratio was varied. SEM revealed profound distortions in coating texture with a high proportion of either solvent in the coating solution. Increasing the amount of either water or alcohol in the coating solution increased the roughness of coated surface which contributed to a burst release of drug due to early opening of the tablet as a result of the high osmotic pressure and low mechanical strength of the coated layer. The optimum coating solvent ratio for spray-coating the osmotic tablets was water : alcohol (60:34) and it resulted in a coating with smooth texture and which successfully modulated drug release lag time of the coated tablets.

Conclusion: The optimum ratio of water/alcohol (60:34) as coating solvent produced a smooth coated tablet surface texture and modulated the drug release lag time of the tablets.
\end{abstract}

Key words: Coating solvent, Drug release, Lag time, Osmotic tablet, HPMC, Methacrylic acid co-polymers 


\section{INTRODUCTION}

Hydro-alcohol solvent systems are extensively used in the pharmaceutical field to apply functional and/or nonfunctional coating of tablets. Good product performance, including uniformity of coating and drug release, is a strong function of these coatings. Uniformity of tablet coating is extremely important as it affects the organoleptic quality of tablets and functionality of the coating, especially for modified release formulations ${ }^{1,2}$. The texture of coated membranes can affect drug release and lag time, which are important parameters in modified-release oral dosage forms ${ }^{1-3}$. Among modified-release oral dosage forms, increasing interest has been shown in systems designed to achieve time-specific (delayed, pulsatile) and site-specific delivery of drugs ${ }^{4,5}$. In particular, systems for delayed release are meant to deliver the active principle after a programmed period following administration. These systems constitute a relatively new class of devices, the importance of which is especially connected with recent advances in chronopharmacology ${ }^{6}$.

By now it is well-known that the symptomatology of a large number of pathologies as well as the pharmacokinetics and pharmacodynamics of several drugs follow temporal rhythms, often resulting in circadian variations. Therefore, the possibility of exploiting delayed release to perform chronotherapy is quite appealing for those diseases. The delay in the onset of release has so far mainly been achieved through osmotic mechanism, coating with hydrophilic or hydrophobic layers as swellable and semi permeable films, swelling, and erodible plug sealing of insoluble capsule body ${ }^{7}$. In addition, multiple coating technology has been applied to chronopharmaceutical dosage forms to achieve the desired lag time and release of drug ${ }^{8}$.

In the present investigation, a combination of approaches was used to develop the coated tablet formulation. HPMC was applied as a swelling layer while Eudragit RSPO/RLPO was used to provide a semi-permeable membrane for delayed release. The study mainly focused on the investigation of the influence of hydro-alcohol coating solvent ratio (water/ethanol) on the surface texture and drug release lag time of a coated porous osmotic tablet. Theophylline (TP), which is a useful drug in the management of nocturnal asthma, was used as the test drug in view of its effectiveness when administered at specific times in relation to onset of symptoms $^{9,10}$.

\section{EXPERIMENTAL}

\section{Materials}

Theophylline (Bukul Aromatics and Chemicals., India) was chosen as the model drug for this study; methacrylic acid copolymers (Eudragit ${ }^{\circledR}$ RS-PO and RL-PO) were supplied free of charge by JJ-Degussa Chemicals, Malaysia. Triethylcitrate [TEC] (Fluka, Germany) was selected as plasticizer while hydroxylpropyl methylcellulose (Methocel E5) was obtained free of charge from Colorcon Asea Specific, Singapore. Low-substituted hydroxypropyl cellulose was received as a gift from Shin-Etsu Chemicals, Japan. Sodium chloride (RM Chemicals, Malaysia) was used as the osmotic agent. All other chemicals used were of analytical or reagent grade.

\section{Methods}

As mentioned in the introduction, the objective of the work was to study the effect of solvent ratio on coating texture and the lag time for drug release. The designed osmotic tablet will be further developed to follow pulsatile release. The designed pulsatile tablet is based on combination of two approaches previously attempted: swelling and osmotic pumping mechanism. The pulsatile tablet was fabricated into three stages: first, the drug (TP) was directly compressed with the osmotic agent $(\mathrm{NaCl})$ 
and super-disintegrant (LHPC-LH-11); second, tablets were coated with a low viscosity swelling layer (HPMC-E5); third, the tablets were subsequently coated with $\mathrm{pH}$ independent methacrylic acid copolymers (Eudragit RSPO and RLPO) as a semipermeable membrane with TEC as pore forming agent.

\section{Preparation of core tablets}

Tablet cores containing theophylline [TP] (5mg/tablet) were prepared according to the following composition (w/w): theophylline $(5 \%)$, sodium chloride (30\%), microcrystalline cellulose (MCC) [34\%], low-substituted hydroxypropyl cellulose (L-HPC-LH-11) [30\%], magnesium stearate $(0.5 \%)$ and talc $(0.5 \%)$. Sodium chloride was pre-screened through a sieve with an aperture of $120 \mu$. Magnesium stearate and talc were similarly screened through a sieve with an aperture of $250 \mu$. All the ingredients were mixed for 15 min and sieved through a mesh with an aperture of $420 \mu$ five times. Tablets were directly compressed from the mixture using $6.05 \mathrm{~mm}$ shallow-concaved punches on ClitPress High Speed tablet machine (Chemunda Pharma Machine, India). Compression force was set such to yield tablets with a hardness of $4.5 \pm 0.5 \mathrm{~kg} / \mathrm{cm}^{2}$. Tablet hardness was monitored using a tablet hardness tester (model YD-2, Vanguard Pharmaceutical machinery Inc, China).

\section{Preparation of coating formulations}

Varying ratios of water and alcohol (as shown in Table 1) were mixed and HPMC $(5 \% \mathrm{w} / \mathrm{w})$ dispersed in each of the solvent by stirring at room temperature for $5 \mathrm{~h}$. Polyethylene glycol (PEG 400) $[1 \% \mathrm{w} / \mathrm{w}]$ was then added and stirred for $15 \mathrm{~min}$.

Eudragit RSPO/RLPO blends (see Table 1) were similarly prepared at room temperature by adding the polymers slowly to the solvent with stirring. TEC, talc and PEG 6000 were added and stirred further for $30 \mathrm{~min}$.
The viscosity of HPMC coating solution was measured with a Brookfield viscometer, USA.

\section{Coating method}

The tablets were warmed in an oven for 15 $\mathrm{min}$ at $45 \pm 0.5{ }^{\circ} \mathrm{C}$ and transferred to $\mathrm{a}$ coating facility (Kothari Pharma Overseas, India). HPMC was applied as a swelling layer by spraying. After drying for $15 \mathrm{~min}$ in an oven at $50.0 \pm 0.5{ }^{\circ} \mathrm{C}$, the tablets were coated with the Eudragit formulation to provide a semi-permeable membrane, based on the coating parameters shown in Table 1. The ratio of Eudragit $R S$ to $R L$ was 2:1. The coating level was determined based on the weight gain of 20 placebo tablets, which were coated at the same time as the test tablets. The tablets were dried in an oven at $55 \pm 0.5$ ${ }^{\circ} \mathrm{C}$ for $4 \mathrm{~h}$ to remove residual solvent from the coating.

\section{Assessment of the morphology of coated tablet surface}

Double layer coated tablets were coated with gold on one side by an ion sputter coater (Polaron SC515, Fisons Instruments, UK) at $50 \mathrm{~mA}$ for $120 \mathrm{sec}$. Gold coated surface of tablet was evaluated by scanning electron microscopy (Leo Supra 50 VP, Germany) to assess the surface texture of the Eudragit polymer layer.

\section{In vitro evaluation of drug release lag time}

In vitro drug release (dissolution) studies were performed as per USP paddle method at $37.0 \pm 0.5^{\circ} \mathrm{C}$ in simulated gastric fluid (SGF, $\mathrm{pH}$ 1.2) and simulated intestinal fluid (SIF, pH 6.8) with the paddle rotating at 100 $\mathrm{rpm}$. Samples $(5 \mathrm{~mL})$ were withdrawn at predetermined time intervals and replaced with equal volume of media. The concentration of TP released from the coated tablets was measured by UV absorption spectroscopy (Hitachi U-2000, Japan) at 276 $\mathrm{nm}$. 
Table 1: Coating parameters

\begin{tabular}{|c|c|c|c|}
\hline \multicolumn{2}{|l|}{ Parameter } & HPMC Layer & Eudragit RS and RL Layer \\
\hline \multicolumn{2}{|l|}{ Batch size $(\mathrm{g})$} & 50 & 50 \\
\hline \multicolumn{2}{|l|}{ Spray rate } & $2 \mathrm{ml} / \mathrm{min}$ & $1 \mathrm{ml} / \min$ \\
\hline \multicolumn{2}{|c|}{ Product temperature } & $\begin{array}{l}40-44^{\circ} \mathrm{C} \text { (inlet temperature: } \\
46-48^{\circ} \mathrm{C} \text { ) }\end{array}$ & $\begin{array}{l}36-38^{\circ} \mathrm{C} \text { (inlet temperature: } \\
40-42^{\circ} \mathrm{C} \text { ) }\end{array}$ \\
\hline \multicolumn{2}{|l|}{ Rotating rate } & $20 \mathrm{rpm}$ & 20 rpm \\
\hline \multicolumn{2}{|c|}{ Spray air pressure } & $0.8 \mathrm{Kg} / \mathrm{cm}^{2}$ & $0.6 \mathrm{Kg} / \mathrm{cm}^{2}$ \\
\hline \multirow{2}{*}{\multicolumn{2}{|c|}{$\begin{array}{l}\text { Coating formulation } \\
\text { composition }\end{array}$}} & HPMC / PEG 400 & Eudragit RS and RL/TEC/ talc \\
\hline & & $5: 1$ & /PEG 6000 \\
\hline & & & $5.0: 0.5: 0.3: 0.04$ \\
\hline \multirow{4}{*}{ Water/ethanol } & $\mathrm{F} 1$ & $80: 14$ & $80: 14$ \\
\hline & $\mathrm{F} 2$ & $60: 34$ & $60: 34$ \\
\hline & F3 & $45: 49$ & $45: 49$ \\
\hline & $\mathrm{F} 4$ & $30: 64$ & $30: 64$ \\
\hline
\end{tabular}

All dissolution tests were performed in triplicate. For each sample, a linear regression was carried out on the linear part of the dissolution curve. Dissolution rate was computed as the slope of the regression line while lag-time is the extrapolated intersection with the time axis.

\section{RESULTS}

\section{Viscosity of HPMC coating solution:}

No significant change was found in the viscosity of HPMC solution prepared with varying ratios of hydroalcohol solutions. Viscosity was $5.5 \pm 0.1,5.6 \pm 0.12,5.6 \pm 0.2$, and $5.7 \pm 0.1 \mathrm{cps}$ (mean $\pm \mathrm{SD}, \mathrm{n}=3$ ) for water/alcohol ratio of $80: 14,60: 34,45: 49$, and 30:64, respectively. This indicates that drug release lag time would not have been influenced by the viscosity of HPMC coating solution.

\section{In vitro theophylline release lag time}

In vitro release lag time data for the osmotic tablets in SGF (see Fig 1) and SIF (see Fig 2) did not differ significantly $(P<0.05)$. Tablets coated with polymers based on water/alcohol solvent ratios of 80:14 (F1) and 30:64 (F4) showed burst drug release, while tablets coated with polymers based on water/alcohol solvent ratios of 60:34 (F2) exhibited increased lag time of approx. $6 \mathrm{~h}$ compared to tablets coated with polymer based on water/alcohol solvent ratios of 45:49 (F3) which also showed delayed release followed by burst release. F2 showed further extended lag time release (see Figs 1 and 2).

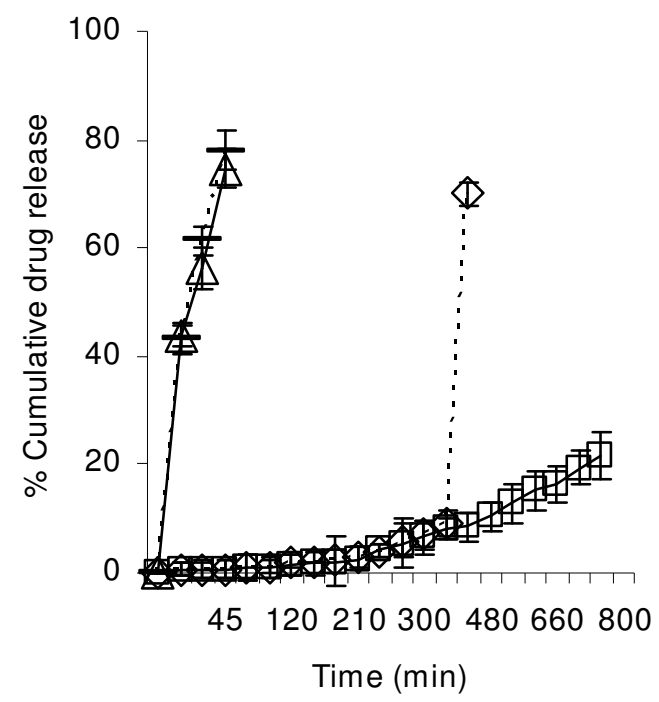

Fig 1: Comparative in vitro release profiles of tablets in SGF coated with coating solution containing different ratio of water and alcohol, in simulated intestinal fluid at $\mathrm{pH}$ 6.8. $(\mathrm{F} 1=-; \mathrm{F} 2=$ $\square ; F 3=\diamond ; F 4=\Delta$ ). 


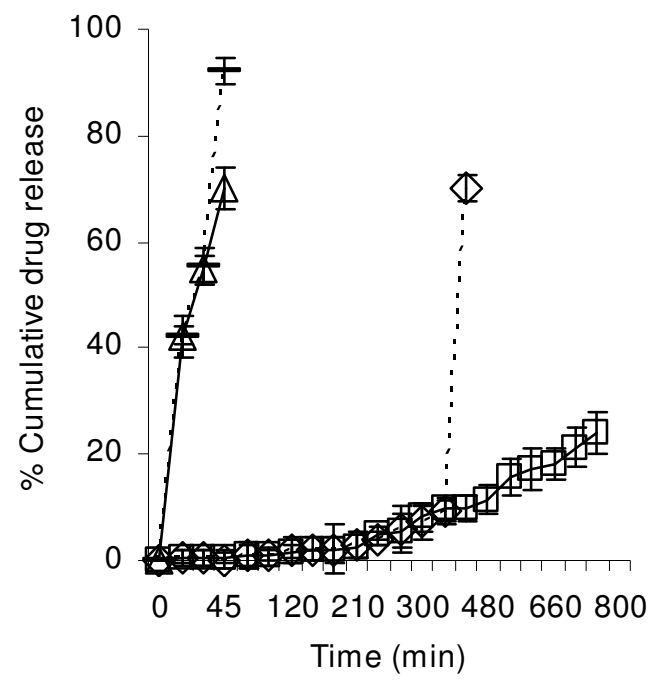

Fig 2: Comparative in vitro release profiles of tablets in SIF coated with coating solution containing different ratio of water and alcohol, in simulated intestinal fluid at $\mathrm{pH}$ 6.8. $(\mathrm{F} 1=-; \mathrm{F} 2=$ 口; F3 $=\diamond ; F 4=\Delta$ ).
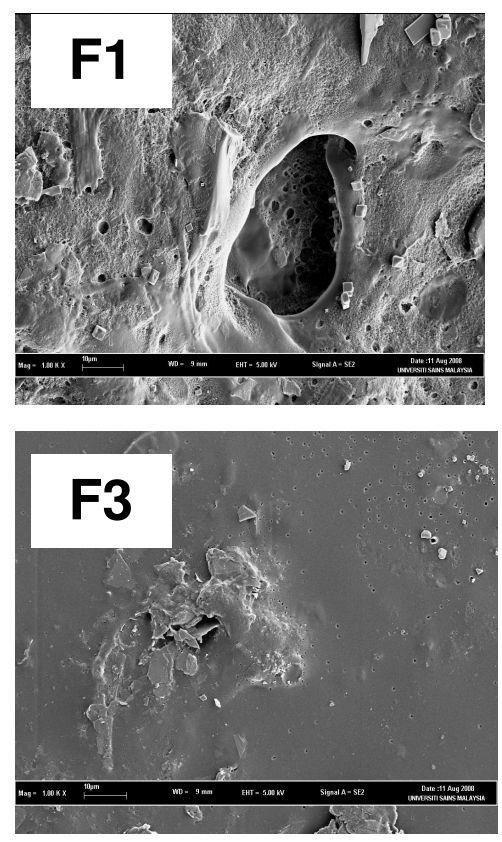

\section{Surface morphology of coated tablets}

The surface morphology and cross-sectional view of coated tablets evaluated by SEM are shown in Fig 3. Tablets coated with polymers using water/alcohol solvent ratios 80:14 and 30:64 resulted in a rough surface with cracks (see Fig 3a and Fig 3d) while those based on water/alcohol ratio of 60:34 showed the smoothest surface (see Fig $3 \mathrm{~b}$ ) with very fine pores. The coating solution based on a water/alcohol ratio of $45: 49$ showed a slightly rough surface with few cracks (see Fig $3 c$ ).

\section{DISCUSSION}

Directly compressed theophylline tablets can be easily coated with hydro-alcohol coating formulations of HPMC and methacrylic acid co-polymers using spray coating method. The surface morphology of the tablets was satisfactory for those coated with formulations based on water/alcohol solvent
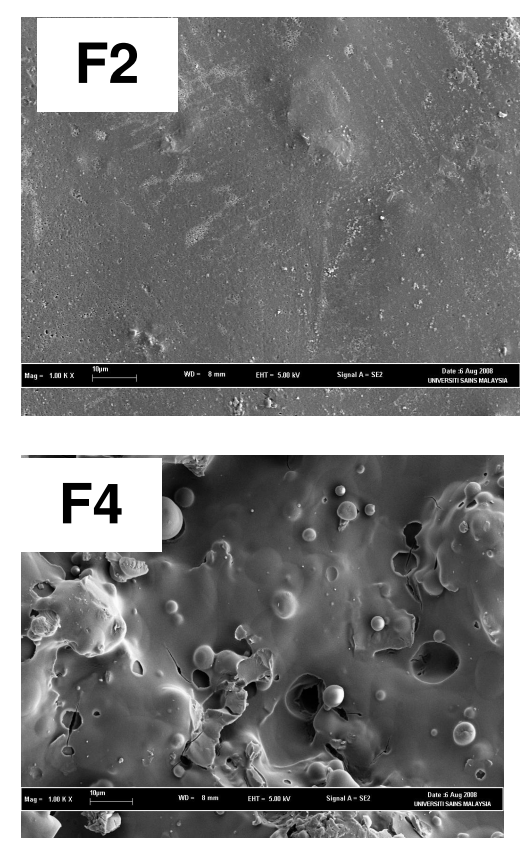

Fig 3: Scanning electron micrographs of tablet surface coated with HPMC and Eudragit RS and RL in water : alcohol ratio of (a) 80:14 (F1); (b) 60:34 (F2); (c) 45:49 (F3); and (d) 30:64 (F4) 
ratio of 60:34 (Fig 3b) leaving a good film formation on the tablet core ${ }^{91}$. Increasing either the amount of water or alcohol in the coating solution beyond this ratio resulted in increase in coated surface roughness (F1 and F4) as shown in Figs $3 a$ and $3 d$. Roughness of coated surface contributed to decreased drug release lag time which could be due to the formation of fractures in the coated layer as a result of low mechanical strength ${ }^{13,14}$. These fractures might have facilitated rapid movement of dissolution media into the tablets since high osmotic pressure exists across the membrane and dissolution media due to the presence of osmotic agent $(\mathrm{NaCl})$ in the tablet core.

Surface roughness of the coated film (see Fig 3a) was high in tablets coated with the formulation based on water/alcohol ratio of 80:14 (F1). The roughness and fracture of F1 coated tablets could be due to the prolonged presence of residual solvent on the surface of the tablet as a result of slow evaporation rate and sticking of the tablets to the coating pan during the tablet coating process. Slow evaporation in F1 could be due to the high proportion of water in the coating solvent system. On the other hand, the rough surface of tablets coated with formulation based on water/alcohol solvent ratio of 30:64 (F4), as shown in Fig $3 d$, can be attributed to the rapid rate of solvent evaporation (due to the high alcohol content of the solvent system), which did not allow formation of continuous coating film, thus leaving behind cracks after tablet during drying. Rapid evaporation is attributed to the presence of a high proportion of volatile ethanol. This contrasts with coated tablets based water/alcohol solvent ratio of 60:34 (F2) which gave a smooth surface (Fig $3 b)$ as the alcohol proportion of the solvent mixture seems appropriate for optimum solvent evaporation, resulting in the formation of a smooth film coating. Such a smooth film would be expected to show resistance to penetration of dissolution medium and hence passage of dissolution fluid into the tablet core, leading to increased lag time ${ }^{12}$.
Coated tablets based on water/alcohol solvent ratio of 45:49 (F3) showed moderate surface smoothness (Fig 3c). This may be due to the higher proportion of alcohol than in coating formulation F2 which leads to a faster evaporation of coating solvent than the optimum solvent evaporation rate observed for F2. Expectedly, cracks and pores in the coating resulted in burst release for $\mathrm{F} 1$ and F4 coating formulation.

The lack of significant difference $(p<0.05)$ between the lag time in simulated gastric fluid $(\mathrm{pH} 1.2)$ and simulated intestinal fluid $(\mathrm{pH}$ 6.8) may be due to the outer coat which are composed of methacrylic acid co-polymers whose solubility are $\mathrm{pH}$-independent ${ }^{15}$. The similarity of the viscosity of HPMC solutions prepared with varying water/alcohol solvent mixtures would also mean that ratio of the solvent mixture would be unlikely to affect drug release lag time ${ }^{16}$.

\section{CONCLUSION}

Based on the foregoing, it can be concluded that the formulation of theophylline osmotic tablets for pulsatile release with the desired lag time is feasible if the water/alcohol solvent ratio for HPMC and methacrylic acid co-polymers is carefully selected. In this regard, an optimum water/alcohol solvent ratio of 60:34 for the coating polymers was found.

\section{ACKNOWLEDGEMENTS}

The authors wish to thank Puan Gemila and Mr. Muttu of School of Biology, Universiti Sains Malaysia, Pulau Pinang, Malaysia for helpful comments and advice during scanning electron microscopic evaluation. Financial support for the work from Research and Innovation Division, Universiti Sains Malaysia (USM), Malaysia, is also acknowledged. Our special thank to USMFellowship for their continuous support. 


\section{REFERENCES}

1. Bhagwant DR, John G, Jim HK. Identification of critical process variables for coating actives onto tablets via statistically designed experiments. Int J Pharm, 2002; 237: 87-94.

2. Elaine SKT, Celine VL, Dawn ZL, Xiaohua $L$ Anthony JW, Paul WSH. Study of coat quality of tablets coated by an on-line supercell coater. AAPS PharmSciTech, 2007; 8: E1-E7

3. Mikko J, Bert VV, Kai-Erik P, Jarkko K, Valtteri K, Raimo S, Tuula TP. Local and average gloss from flat-faced sodium chloride tablets. AAPS PharmSciTech, 2006; 7: E1-E6.

4. Yuichi O, Yukinao W, Hirokazu O, Kazumi D. Development of dividable one-step dry-coated tablets (Dividable- OSDRC) and their evaluation as a new platform for controlled drug release. Pharm Res, 2004: 21: 1177-1183.

5. Schellekens RCA, Stellaard $F$, Mitrovic $D$, Stuurman FE, Kosterink JGW, Frijlink FW. Pulsatile drug delivery to ileo-colonic segments by structured incorporation of disintegrants in pH-responsive polymer coatings. J Control Rel, 2008; 132: 91-98.

6. Sangalli ME, Maroni A, Zema L, Busetti C. In vitro and in vivo evaluation of an oral system for time and/or site-specific drug delivery. J Control Rel, 2001; 73: 103-110.

7. Libo Y, James SC, Joseph AF. Colon specific drug delivery: new approaches and in vitro/in vivo evaluation-review. Int J Pharm, 2002; 235: 115.

8. Srisagul $S$, Satit $P$, Ornlaksana $P$, Andrei $D$, Roland $B$. Development of pulsatile release tablets with swelling and rupturable layers. J Control Rel, 2004; 95: 147- 159.

9. Gwen SS. Nocturnal asthma: mechanisms and management. Mount Sinai J Med, 2002; 69: 140-147.

10. Gothaskar AV, Joshi AM, Joshi NH. Pulsatile drug delivery system-a review. Drug Del Tech, 2004; 4: 1-14

11. Cung AN, Yvette Niamien KK, Eric A, Eric D, David $Q G$, Hatem F, Robert G. Preparation of surfactant-free nanoparticles of methacrylic acid copolymers used for film coating. AAPS PharmSciTech, 2006; 7: E1-E7.

12. Qureshi J, Mohd Amir, Alka A, Sanjula B, Ali J. Chronomodulated drug delivery system of sulbutomol sulphate for the treatment of nocturnal Asthma. Ind J Pharm Sci, 2008; 70: 351-356.

13. Shahrzad M, Reza F. A novel approach in the assessment of polymeric film formation and film adhesion on different pharmaceutical solid substrates. AAPS PharmSciTech, 2004; 5: 1-8.

14. Briscoe BJ, Akram A. The influence of solvent quality on the mechanical properties of thin cast isotactic poly(methyl methacrylate) coatings. J Mater Sci, 2002; 37: 4929 - 4936.

15. Azarmi S, Farid J, Nokhodchi A, Bahari-Saravi SM, Valizadeh $H$. Thermal treating as a tool for sustained release of indomethacin from eudragit $R S$ and $R L$ matrices. Int $J$ Pharm, 2002; 246: 171-177.

16. Qing RC, Han GC, Dong CK, Lee BJ. Release behavior and photo-image of nifedipine tablet coated with high viscosity grade hydroxypropylmethylcellulose: effect of coating conditions. Int J Pharm, 2004; 274: 107-117. 